\title{
Vorsprung durch Verfahrensintegration - Zukunft hat, wer Zukunft schafft
}

Liebe Leserin, lieber Leser,

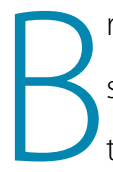
ranchen- und produktübergreifend haben inzwischen Leichtbauprodukte unterschiedlicher Facetten Einzug in unseren Alltag gehalten - ohne dass sie von uns besonders wahrgenommen und thematisiert werden. Man denke nur an die Verpackungsindustrie und die extrem leichten Getränkedosen aus Aluminium. Um bei gleichen Gebrauchseigenschaften eine derartige Dose noch leichter, noch ressourcenschonender, das heißt noch nachhaltiger herzustellen, bedarf es höchster Innovationskraft.

Bei der effizienten Prozessgestaltung von Leichtbaustrukturen aus kohlenstofffaserverstärkten Kunststoffen (CFK) kommt verschärfend noch die Anisotropie als richtungsweisendes Auslegungsmerkmal hinzu. Insbesondere bei faserverbundintensiven Mischbauweisen sind daher neuartige und angepasste konstruktiv-technologische Lösungskonzepte zu entwickeln.

Große Chancen für zukünftige Entwicklungen von hybriden Bauteilen mit ihrem einsatzgerecht einstellbaren Eigenschaftsspektrum und ihrer hohen Funktionsintegration liegen darin, die unterschiedlichen Werkstoffe nicht erst ganz am Schluss zu verbinden, sondern bereits in einem frühen Stadium die Herstellungsprozesse zusammenzuführen. Durch die Kombination der unterschiedlichen werkstoffspezifischen Fertigungsverfahren in eine integrale Prozesskette ist in besonderem Maße die notwendige Material- und Ener- gieeffizienz wettbewerbsfähiger Produkte zu erreichen. Dies stellt allerdings große Herausforderungen auch bei der Integration der unterschiedlichen Maschinen und Anlagen, etwa hinsichtlich miteinander vernetzter beziehungsweise kompatibler, robuster Prozessketten.

Diesen Vorsprung durch Verfahrensintegration gilt es gewinnbringend zu nutzen - trotz notorischer Bedenkenträger, aber mithilfe innovationsfreudiger Einkäufer. In dieser Ausgabe von lightweight design werden verschiedene Lösungsansätze sowohl bei der Material- und Bauteilentwicklung als auch bei der technologischen Umsetzung aufgezeigt.

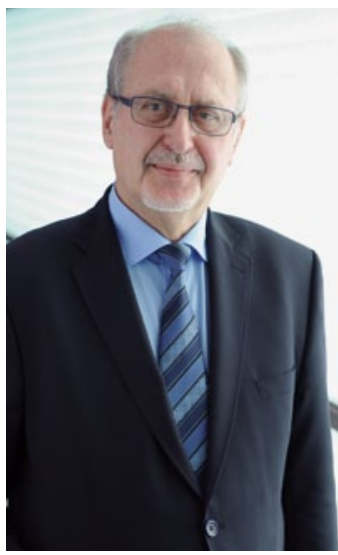

Prof. Dr.-Ing habil. Prof. E.h. Werner Hufenbach, Direktor des Instituts für Leichtbau und Kunststofftechnik ILK an der TU Dresden 